\title{
MORFOMETRI LERENG KAWASAN SUB-LITORAL PANTAI MALALAYANG II KOTA MANADO
}

\author{
(Slope Morphometric of Sub-Littoral Zone in Malalayang II Coast-Manado)
}

\section{Brama G. Djabar ${ }^{1 *}$, Rignolda Djamaluddin1, Royke M. Rampengan'}

1. Program Studi Ilmu Kelautan Fakultas Perikanan dan Ilmu Kelautan Universitas Sam Ratulangi, Manado.

*e-mail : bdjabar@gmail.com

Best knowledge about slope morphometric is needed to support the usage of coastal area. This research is aimed to descript bathymetry and current pattern at sub-littoral zone of Malalayang II Coast, and to analyze the pattern in relation to coastal area change. Lagrangian method was applied to measure current velocity and direction, and in the field water depth was also measured. The result indicated that west part of coastal area was of shallow with a relatively faster current velocity comparing to the east part. Based on bathymetry analysis, the west area was susceptible to erosion. It is recommended from this research that there is a need of construction of coastal protection to ensure the safety and future development of settlement on the coast.

Keywords: Malalayang coast, coastal areas, sub-littoral, morphometric, bathymetry, current

Pemanfaatan pantai harus didukung oleh pemahaman yang baik tentang morfometri lereng ruang pantai tersebut. Penelitian ini dilakukan dengan tujuan untuk mendeskripsikan batimetri ruang dan pergerakan arus di kawasan sub-litoral Pantai Malalayang II, serta menganalisis kaitannya terhadap perubahan ruang pantai. Dengan menerapkan metode Lagrangian dan pengukuran kedalaman, diperoleh hasil bahwa ruang pantai bagian Barat memiliki perairan yang dangkal dibandingkan bagian Timur sehingga pergerakan arus relatif cepat di ruang tersebut. Analisis data batimetri menyimpulkan bahwa kawasan ini rentan terhadap erosi pantai, untuk itu disarankan adanya pembangunan pelindung pantai demi keamanan dan pengembangan pemukiman di kawasan Pantai Malalayang II.

Kata kunci : pantai Malalayang, ruang pantai, sub-litoral, morfometri, batimetri, arus

\section{PENDAHULUAN}

Dewasa ini, pemanfaatan ruang pantai sedang giat-giatnya dilakukan. Hal ini harus didukung oleh pemahaman tentang ruang pantai itu sendiri, yaitu menyangkut morfometri lereng ruang pantai. Salah satu kawasan yang rentan terhadap perubahan lahan adalah kawasan sublitoral. Kawasan sub-litoral merupakan kawasan dari batas litoral sampai batas atas paparan benua (shelf), sampai kedalaman 200 meter (Sverdrup et al., 1942). Kawasan ini selalu tergenang air dan masih dipengaruhi oleh aktivitas oseanografi yang bergerak menuju pantai (Bird, 2008). Dikarenakan pengaruh tersebut, maka perubahan lahan pantai bergantung pada proses yang terjadi di kawasan sub-litoral.

Perubahan yang sering terjadi adalah erosi pantai dan deposisi. Faktor yang bertanggungjawab terhadap jalannya fenomena tersebut adalah arus. Arus merupakan gerakkan perpindahan massa air laut, baik secara vertikal maupun horizontal, dan pergerakannya terjadi pada seluruh lautan di dunia (Hutabarat dan Evans, 1986). Arus dipengaruhi oleh berbagai faktor diantaranya pasang surut (pasut), angin, perbedaan densitas, bahkan gelombang saat mendekati pantai (Groves, 1989; Poerbandono dan Djunasjah, 2005). Poerbandono dan Djunasjah (2005) mengemukakan bahwa angin menjadi penyebab timbulnya arus air secara vertikal yang 
dikenal dengan sebutan upwelling dan sinking, sedangkan gerakan air yang luas dapat diakibatkan oleh perbedaan densitas dari lapisan yang mempunyai kedalaman berbeda-beda. Gerakan pasut dapat menimbulkan arus, pada umumnya akan bertambah kuat ketika mencapai pantai dan semakin meningkat pada sirkulasi daerah lokal (Ingmanson and Wallace, 1989). Sedangkan gelombang dapat menjadi penyebab arus sebagai transpor sedimen dalam arah tegak lurus dan sepanjang pantai. Arus yang berfungsi sebagai media transpor sedimen menuju pantai akan melewati kawasan sub-litoral (Pethick, 1992). Pemahaman yang baik mengenai arus, pasang surut dan morfometri lereng di suatu kawasan pantai (terutama kawasan sub-litoral) sangat penting untuk dikaji. Hal ini berkaitan juga dengan adanya pemanfaatan di ruang pantai yang bersangkutan.

Teluk Manado merupakan suatu kawasan pantai yang terletak di bagian Barat Kota Manado, Provinsi Sulawesi Utara. Kawasan ini diapit oleh Tanjung Mandolang pada bagian Barat Daya dan Tanjung Pisok pada bagian Utara (BAKOSURTANAL, 1995). Pantai Malalayang II merupakan kawasan pantai yang terletak di daerah Teluk Manado. Djamaluddin (2012) mengungkapkan bahwa kawasan pantai ini dimanfaatkan sebagai tempat pemukiman. Kondisi ruang pantai ini perlu dikaji, mengingat warga yang bermukim sebagian besar adalah nelayan.

Sesuai hasil observasi di lapangan yang menyimpulkan bahwa sebagian lahan pantai ini berpotensi mengalami erosi sehingga dapat dirumuskan permasalahan yaitu bagaimana perubahan morfologi dasar perairan kawasan sub-litoral di Perairan Malalayang II. Diharapkan dengan memperoleh jawaban terhadap masalah ini, dapat diinterpretasi proses pantai yang berlangsung di kawasan sub-litoral daerah ini.
Penelitian ini diarahkan untuk mencapai tujuan. Adapun tujuan penelitian ini adalah mendeskripsikan batimetri ruang dan pola arus kawasan sub-litoral Pantai Malalayang II serta menganalisis kaitan pola arus dengan morfologi dasar perairan kawasan Pantai Malalayang II.

\section{METODE PENELITIAN}

Penelitian ini menerapkan metode deskriptif terhadap data dan informasi yang diteliti. Pengukuran data arus menggunakan metode Lagrangian, morfologi dasar laut diukur dengan melakukan kegiatan pemeruman, dan data pasang surut menggunakan metode pengamatan langsung. Kegiatan dan pengukuran diarahkan untuk mengungkapkan aspek morfologi pantai berupa morfometri lereng sub-litoral, dan pola arus permukaan di perairan tersebut.

\section{Waktu dan Lokasi Penelitian}

Kegiatan survey lapangan dan pengukuran dilaksanakan pada 11-13 Februari 2017 dan 25-27 Mei 2017. Lokasi penelitian berada di Pantai Malalayang II. Pemukiman nelayan ini berada di belakang halaman Politeknik Kesehatan (Politekes) Malalayang, sehingga akses utama dan satusatunya menuju pemukiman tersebut adalah dengan melewati jalan masuk ke daerah Politekes. Lokasi penelitian ditampilkan pada Gambar 1.

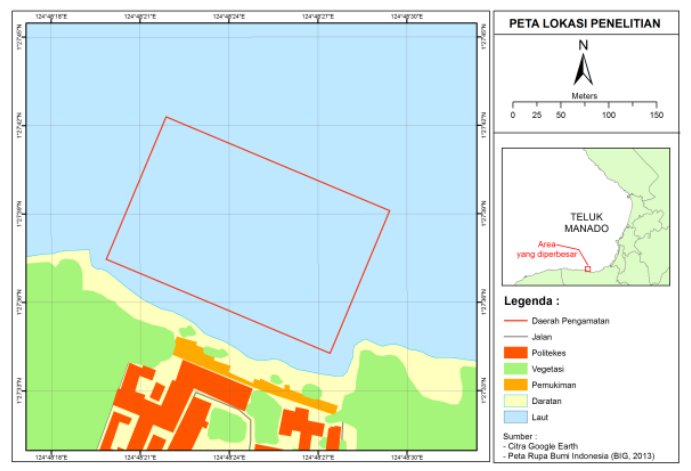

Gambar 1. Peta lokasi penelitian 


\section{Alat dan Bahan Penelitian}

Alat dan bahan yang digunakan dalam penelitian ini adalah Citra Satelit Google Earth (sebagai peta dasar), Kompas, Floater Current Meter (FCM), Perahu, Palem Pasut, GPS Furuno GP39 Navigator, Fish Finder, alat tulis menulis, perangkat lunak : Microsoft Office 2010, ArcGIS 10.2, dan Surfer 13.

\section{Survei dan Pengukuran}

Kegiatan pemeruman (batimetri) menggunakan perahu, fish finder, dan GPS. Pengukuran batimetri dilakukan dengan mengikuti jalur pemeruman yang berada pada posisi geografis $1^{\circ} 27^{\prime} 34^{\prime \prime}-1^{\circ} 27^{\prime} 40^{\prime \prime}$ LU dan 124⒋'20"$124^{\circ} 48^{\prime 2} 28^{\prime \prime}$ BT. Data kedalaman diambil bersamaan dengan posisi geografis dimana kedalaman diukur (titik fix). Hasil yang diperoleh dikoreksi posisi geografis dan data yang terkoreksi kemudian dituangkan pada lembar isian. Bersamaan dengan kegiatan pemeruman, tinggi muka air laut diamati pada palem pasut setiap 10 menit.

Arus diukur dengan alat pengukur yaitu GPS dan Floater Current Meter (FCM) yang terdiri dari pelampung, baling-baling, dan pemberat yang dihubungkan dengan tali. Pengukuran dilakukan saat muka laut mengalami pasang tertinggi dan surut terendah. Fungsi GPS mendata dari titik (posisi koordinat) awal ke titik berikutnya dengan selang waktu 30 detik setiap pengulangan yang dilakukan sebanyak tiga kali pengulangan. Data yang diperoleh kemudian diolah sehingga menghasilkan jarak tempuh, waktu, dan kecepatan arus, sedangkan gerak perpindahan koordinat diolah sehingga menghasilkan arah arus.

Pengukuran pasang surut menggunakan cara pengamatan langsung, yaitu pengamatan yang dilakukan dengan cara membaca skala pada palem pasut yang terkena permukaan air setiap jangka waktu tertentu. Pengamatan dilaksanakan setiap jam selama 39 jam, dan setiap 10 menit selama kegiatan pemeruman.

\section{Pengolahan dan Analisis Data}

Data batimetri yang terkoreksi kemudian dihitung dengan formula sederhana yang lazim digunakan dalam kegiatan pemeruman, yaitu :

$$
\mathrm{H}_{\text {Plot }}=\mathrm{H}_{\mathrm{Ukur}}+\mathrm{H}_{\mathrm{T}}+\mathrm{H}_{\text {Pas }}
$$

Keterangan :

$\mathrm{H}_{\text {Plot }}=$ Kedalaman terkoreksi

$\mathrm{H}_{\text {Ukur }}=$ Kedalaman terukur selama pemeruman

$\mathrm{H}_{\mathrm{T}} \quad=$ Kedalaman Transduser

$\mathrm{H}_{\text {Pas }}=$ Tinggi Muka Air dari MSL

Setelah perhitungan selesai, data kemudian diolah menjadi kontur kedalaman menggunakan software Surfer 13, sedangkan untuk pembuatan peta menggunakan ArcGIS 10.2.

Hasil pengukuran arus berupa titik koordinat yang disalin dari GPS, kemudian diolah untuk menentukan kecepatan dan arah arus. Nilai kecepatan arus dihitung dengan menggunakan persamaan :

$$
\mathrm{V}=\frac{\text { resultan } \mathrm{s}}{\mathrm{t}}
$$

Keterangan :

$$
\begin{aligned}
\mathrm{V} & =\text { kecepatan arus (m/det) } \\
\text { Resultan } \mathrm{s} & =\text { jarak perpindahan FCM } \\
\mathrm{t} & =\text { waktu (detik) }
\end{aligned}
$$

Nilai $s$ (jarak) masing-masing perpindahan ditentukan dengan menggunakan kaidah trigonometri, yaitu :

$$
\begin{aligned}
& \left(s_{1-2}\right)^{2}=\left(X_{1-2}\right)^{2}+\left(Y_{1-2}\right)^{2} \\
& \left(s_{2-3}\right)^{2}=\left(X_{2-3}\right)^{2}+\left(Y_{2-3}\right)^{2}
\end{aligned}
$$

Keterangan :

$\mathrm{S}_{1-2}=$ jarak tempuh dari $\left(\mathrm{X}_{1}, \mathrm{Y}_{1}\right) \mathrm{ke}$ $\left(X_{2}, Y_{2}\right)$

$\mathrm{S}_{2-3}=$ jarak tempuh dari $\left(\mathrm{X}_{2}, \mathrm{Y}_{2}\right) \mathrm{ke}$

$$
\left(\mathrm{X}_{3}, \mathrm{Y}_{3}\right)
$$

Arah arus diperoleh dengan mencari sudut alpha $(\alpha)$. Formula yang digunakan untuk mencari arah arus dan sudut alpha, yaitu : 


$$
\begin{aligned}
& \Theta^{\circ}=\text { sudut istimewa }(+/-) \alpha^{\circ} \\
& \alpha^{\circ}=\operatorname{atg}\left(Y_{3} / X_{3}\right)
\end{aligned}
$$

Keterangan :

$\Theta^{\circ} \quad=$ arah arus

$\alpha^{\circ} \quad=$ sudut alpha

atg = cotangen

Berikut adalah syarat nilai sudut istimewa yang digunakan berdasarkan muatan nilai $X_{3}$ dan $Y_{3}$ pada koordinat:

1. Jika $X=+$ dan $Y=+$, maka arah adalah $90^{\circ}-\alpha$

2. Jika $X=+$ dan $Y=-$, maka arah adalah $90^{\circ}+\alpha$

3. Jika $X=-$ dan $Y=-$, maka arah adalah $270^{\circ}-\alpha$

4. Jika $X=-$ dan $Y=+$, maka arah adalah $270^{\circ}+\alpha$

5. Jika $X=0$ dan $Y=+$, maka arah adalah $0^{\circ}$

6. Jika $X=0$ dan $Y=-$, maka arah adalah $180^{\circ}$

7. Jika $X=+$ dan $Y=0$, maka arah adalah $90^{\circ}$

8. Jika $X=-$ dan $Y=0$, maka arah adalah $270^{\circ}$

Setelah perhitungan dan analisis selesai, data tersebut kemudian diolah untuk dijadikan peta pola arus dengan menggunakan Surfer 13.

\section{HASIL DAN PEMBAHASAN}

\section{Morfologi Dasar Laut}

Kegiatan

pemeruman menghasilkan data yang tersimpan dalam kartu penyimpanan data pada GPS. Hasil pengukuran batimetri kemudian disalin dan dikoreksi dengan data pengamatan pasut selama pemeruman. Proses penggambaran morfologi dasar laut menggunakan perangkat lunak Surfer 13. Hasil dari penggambaran tersebut berupa garisgaris kontur kedalaman yang merupakan interpolasi dari titik-titik pengukuran kedalaman yang tersebar pada lokasi pengukuran. Visualisasi dari garis-garis kontur kedalaman pengukuran Februari dan Mei disajikan berupa peta batimetri yang ditampilkan pada Gambar 2 dan 3.

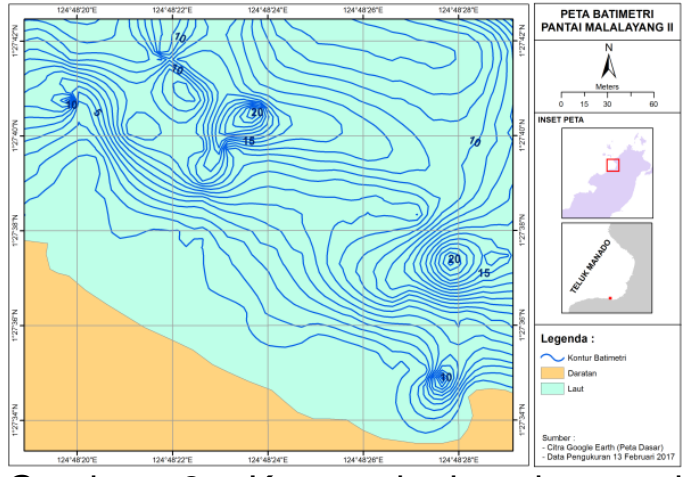

Gambar 2. Kontur batimetri pantai Malalayang II (Februari)

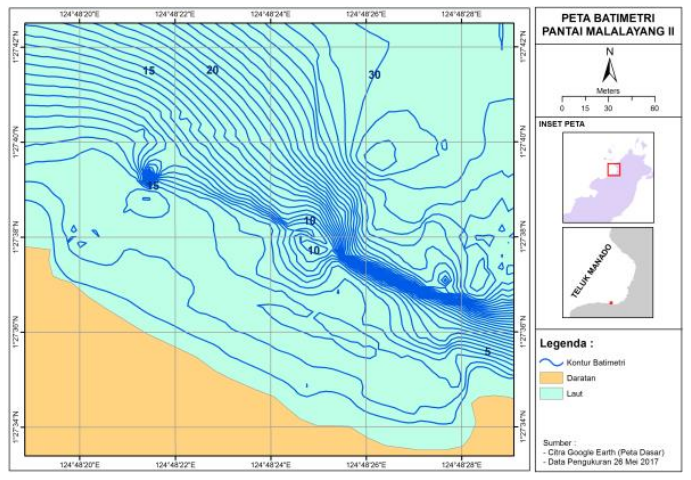

Gambar 3. Kontur batimetri pantai Malalayang II (Mei)

Gambar diatas memperlihatkan kawasan pemeruman yang dapat teramati ditunjukkan oleh beberapa posisi geografis. Batas kawasan yang terlihat berada pada posisi $1^{\circ} 27^{\prime} 34^{\prime \prime}$ $1^{\circ} 27^{\prime} 42^{\prime \prime}$ LU dan 124ㄴㅇ' $20^{\prime \prime}-124^{\circ} 48^{\prime} 28^{\prime \prime}$ BT. Pada peta batimetri yang dihasilkan, terdapat garis-garis kontur yang berdekatan (berimpitan) pada ruang tertentu dan adapula garis kontur yang berjauhan pada ruang lainnya. Pada ruang pantai bagian Barat, garis kontur terlihat memiliki jarak yang agak berjauhan antar garis, sedangkan bagian Timur memperlihatkan garis kontur yang berimpitan. Pipkin et al., (1987) menyatakan bahwa jarak garisgaris kontur yang berdekatan menandakan lereng yang curam atau perubahan kedalaman secara tiba-tiba, sedangkan garis-garis kontur yang berjauhan bertanda bahwa perubahan kedalaman tersebut memiliki interval yang jarang.

Nilai kedalaman maksimum pada pemeruman bulan Februari 
adalah 23 meter, sedangkan bulan Mei adalah 32 meter. Perbedaan kedua tampilan hasil pengukuran terlihat pada lekukan garis kontur, dimana lekukan pemeruman bulan Mei terlihat lebih rapat dibandingkan bulan Februari.

\section{Arus}

Hasil pengukuran arus berupa data titik koordinat yang kemudian diolah untuk mendapatkan kecepatan dan arah arus. Pengolahan data arus menggunakan Microsoft Excel, sedangkan untuk visualisasi pola arus menggunakan Surfer 13. Hasil pengolahan tersebut kemudian dibahas untuk mendeskripsikan arus permukaan di Pantai Malalayang II pada dua waktu yang berbeda. Untuk itu, dipisahkan pembahasan antara arus bulan Februari dan Mei, baik saat pasang maupun surut.

\section{Arus Bulan Februari}

Pengukuran arus pada bulan Februari dilakukan pada malam hari fase umur bulan purnama. Hal ini dikarenakan fakor cuaca yang tidak mendukung sehingga memungkinkan aktivitas di wilayah tersebut harus diwaspadai. Arus diukur saat keadaan muka air berada pada pasang tertinggi dan surut terendah. Kecepatan arus yang terukur saat pasang berkisar 0,099-0,483 knot dan saat surut, berkisar 0,207-1,164 knot. Visualisasi pola arus saat pasang dan surut hasil interpolasi software Surfer 13 disajikan dalam bentuk peta.

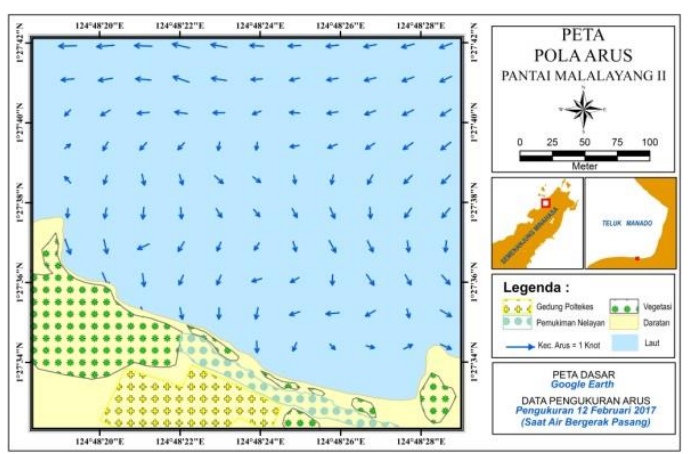

Gambar 4. Pola arus saat pasang Februari

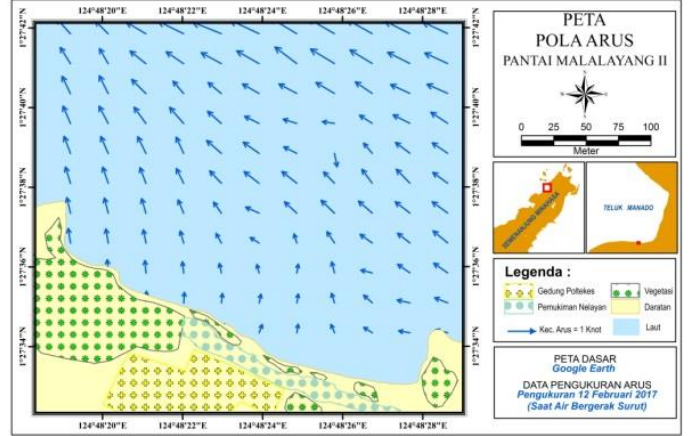

Gambar 5. Pola arus saat surut Februari

Pergerakan arus pada saat pasang terlihat mengalir masuk menuju garis pantai, sedangkan pada saat surut arus bergerak keluar dari daerah pantai. Hal ini diasumsikan karena pergerakan air saat pasang membawa massa air dengan jumlah yang besar sehingga air laut berperan untuk mengisi kekosongan di perairan pantai. Sedangkan pada saat surut, pergerakan air keluar dari daerah pantai terjadi secara stabil dan konstan meskipun dipengaruhi oleh tiupan angin. Pada bagian Utara peta pola arus, terlihat bahwa kecepatan arus maksimum terjadi di bagian tersebut dengan pergerakan menuju ke arah Barat. Sedangkan bagian Selatan, kecepatan arus mulai menurun saat mendekati pantai.

\section{Arus Bulan Mei}

Pergerakan arus pada bulan Mei berbeda dengan bulan Februari. Hal ini dimungkinkan karena adanya perbedaan musim pada pengukuran dua waktu tersebut.

Arus pada bulan Mei diukur pada fase umur bulan baru. Pengukuran dilakukan pada pukul 18.00 WITA (saat pergerakan air pada pasang tertinggi), dan pukul 00.00 WITA (saat air berada pada surut terendah). Pergerakan arus tergambar tidak teratur. Pergerakan arus yang terbentuk dari hasil pengolahan data dan hasil interpolasi Surfer 13 kemudian digambarkan dalam bentuk peta. 


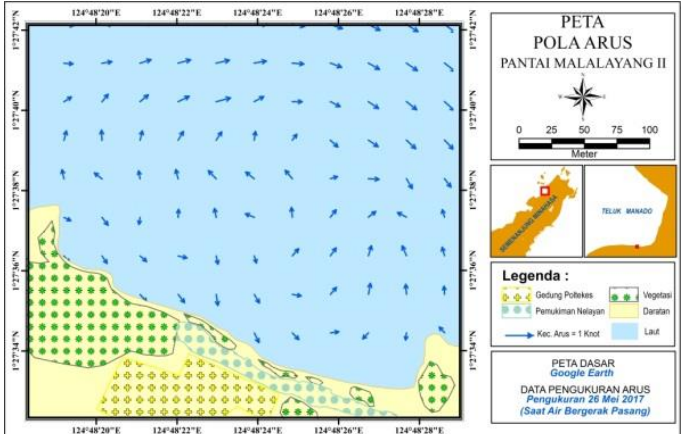

Gambar 6. Pola arus saat pasang Mei

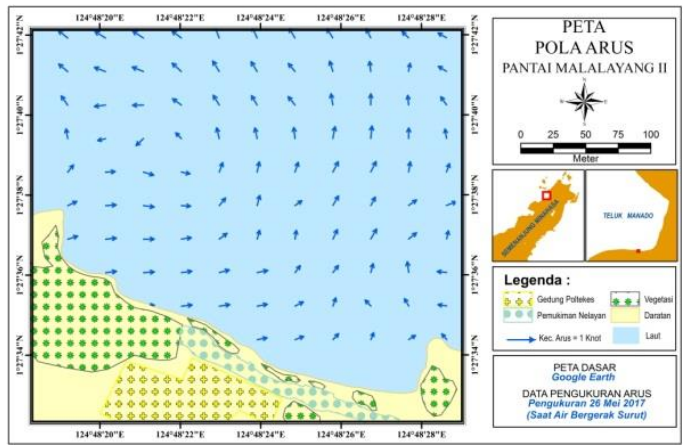

Gambar 7. Pola arus saat surut Mei

Saat pasang, arus bergerak dari arah Barat menuju ke Timur pada bagian Utara peta dan terlihat bergerak kembali dari arah sebaliknya. Sedangkan pergerakan arus di bagian Selatan peta terlihat tidak teratur dan kecepatannya terkesan mulai menurun. Saat air bergerak surut, massa air bergerak meninggalkan pantai. Air bergerak keluar mengarah ke Utara seiring dengan fenomena pasang surut, kemudian berputar mengarah Barat dan belok ke arah Timur.

Kecepatan arus saat pasang maupun surut pada bulan Mei bervariasi. Saat pasang, kecepatan arus maksimum yang terukur adalah 0,364 knot sedangkan pengukuran saat surut adalah 0,292 knot. Pengukuran saat pasang mulai dilakukan saat masa air berada di titik puncak pasang sehingga dalam kegiatan pengukuran air perlahan mulai bergerak turun. Begitu juga sebaliknya saat pengukuran mulai dilakukan saat keadaan air pada surut terendah.

Salah satu faktor yang mempengaruhi hal tersebut adalah energi angin musim. Pergerakan arus pada bulan Februari masih dipengaruhi oleh Musim Barat, sedangkan arus yang bergerak saat bulan Mei dipengaruhi oleh Musim Peralihan. Wyrtki (1961) mengemukakan bahwa Musim Barat, tiupan angin bergerak dari arah Barat menuju Timur sehingga pergerakan arus permukaan mengikuti energi angin tersebut, sedangkan Musim Peralihan dikatakan bahwa pergerakan arus permukaan terjadi secara tidak teratur.

Berdasarkan peta arus yang dihasilkan, tampak arus bergerak keluar dan masuk seiring dengan fenomena pasang surut. Sehingga pasut dianggap menjadi faktor yang paling berpengaruh dan mempunyai peran dominan dalam sirkulasi air laut di teluk.

Secara visual, lahan sub-litoral yang diobservasi menunjukkan adanya interaksi antara pergerakan arus dengan morfologi dasar perairan kawasan tersebut. Perbedaan waktu pengukuran yang dilakukan untuk membandingkan perubahan dasar laut kawasan sub-litoral agar bisa menelaah bagian ruang pantai yang mengalami erosi dan deposisi.

Telaah dan analisis sebaran erosi dan deposisi menggunakan ArcGIS 10.2 dengan cara tumpang susun (overlay) data hasil batimetri yang didapat. Hal ini dilakukan agar bisa melihat peran arus dalam perubahan ruang pantai sub-litoral kawasan Malalayang II. Hasil overlay tersebut kemudian dianalisis agar bisa mengetahui luas area dan volume sebarannya.

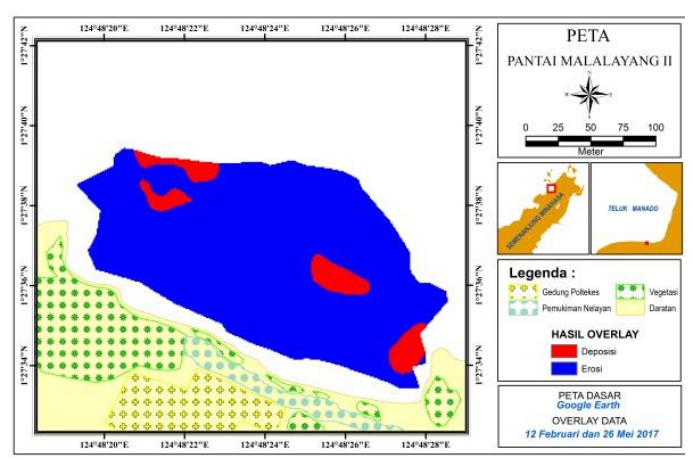

Gambar 8. Sebaran erosi dan deposisi 
Tabel 1. Sebaran erosi dan deposisi perairan Malalayang II

\begin{tabular}{crr}
\hline No & $\begin{array}{c}\text { Volume } \\
\text { Erosi/Deposisi } \\
\left(\mathrm{m}^{3}\right)\end{array}$ & $\begin{array}{c}\text { Luas } \\
\text { Area } \\
\left(\mathrm{m}^{2}\right)\end{array}$ \\
\hline 1 & $-139.656,19$ & 29.136 \\
2 & 489,23 & 638 \\
3 & 169,813 & 442 \\
4 & 958,60 & 829 \\
5 & $1.577,11$ & 710 \\
6 & $-12,644$ & 28 \\
7 & $-0,01$ & 1 \\
\hline Erosi & $-139.668,84$ & 29.165 \\
Deposisi & $1.617,64$ & 2.619 \\
\hline
\end{tabular}

Berdasarkan ruang lingkup pemeruman, fenomena erosi terjadi hampr seluruh daerah pantai. Luas area yang tergerus mencapai 29.165 $\mathrm{m}^{2}$, hampir menutupi keseluruhan daerah pemeruman yang luasnya adalah $31.784 \mathrm{~m}^{2}$.

Menurut Poerbandono dan Djunarsjah (2005), arus sangat berperan terhadap laju sedimen yang terakumulasi. Pergerakan arus dapat digunakan untuk memperkirakan besarnya energi yang bekerja di dasar perairan dan mampu berperan sebagai transpor sedimen, sehingga kejadian ini mengakibatkan terjadinya erosi atau sedimentasi.

Terlihat sebaran volume erosi dan deposisi yang terjadi pada dua waktu berbeda (Februari dan Mei) lebih didominasi oleh fenomena erosi yaitu berkisar -139.668,84 $\mathrm{m}^{3}$. Hal ini menandakan bahwa peran arus dalam penyebaran partikel sedimen sangat berpengaruh terhadap kawasan sublitoral. Penelitian ini menjawab peran arus dalam kaitannya dengan perubahan morfologi dasar perairan, sehingga disarankan adanya perencanaan pembuatan pelindung pantai agar bisa mengurangi dampak erosi terhadap pemukiman nelayan di sekitar Pantai Malalayang II.

\section{KESIMPULAN}

Kesimpulan dari penelitian ini adalah batimetri kawasan sub-litoral dideskripsikan memiliki topografi dasar laut yang berbeda. Ruang pantai bagian Barat memiliki perairan yang dangkal dibandingkan ruang pantai bagian Timur. Hal ini juga didukung oleh pergerakan arus yang relatif lebih cepat di ruang pantai bagian Barat. Keterkaitan antara pergerakan arus dan topografi perairan mempengaruhi perubahan morfologi dasar laut dikarenakan peran arus sebagai transpor sedimen. Informasi ini disarankan dapat digunakan untuk keamanan ruang Pantai Malalayang II agar pengembangan pemukiman yang ada di lokasi penelitian bisa berjalan dengan baik.

\section{DAFTAR PUSTAKA}

BAKOSURTANAL. $1995 . \quad P e t a$ Lingkungan Pantai Indonesia Manado Lembar LPI 2417-03. Jakarta.

Bird, E. 2008. Coastal Geomorphology An Introduction. Second Edition. John Wiley and Sons Ltd. Australia. p 436.

Groves, D. 1989. The Oceans. John Wiley and Sons, Inc. New York. p 203.

Hutabarat, S., Evans, S.M. 1986. Pengantar Oseanografi. UI-Press. Jakarta. 159 hal.

Ingmanson, D.E., Wallace, W.J. 1989. An Introduction Oceanography. A Division Of Wadsworth, Inc. California. p 511.

Pethick, J. 1992. An Introduction to Coastal Geomorphology. Edward Arnold Publication Ltd. London. $\mathrm{p}$ 259.

Pipkin, B.W., Gorsline, D.S., Casey, R.E., Hammond, D.E. 1987. Laboratory Exercises In Oceanography. Second Edition. 
W.H. FreeMan and Company. New York. p 257.

Poerbandono, Djunasjah, E. 2005. Survei Hidrografi. Refika Aditama. Bandung. 166 hal.

Sunarto. 1991. Geomorfologi Pantai. Pusat Antar Universitas IImu Teknik. Universitas Gadjah Mada. Yogyakarta. 52 hal.

Sverdrup, H.U, Martin, W.J., Richard, H.F. 1942. The Oceans Their Physics, Chemistry, and General Biology. University of California. New York. p 1087.

Wyrtki, K. 1961. Physical Oceanography of South East Asian Water. Naga Report Vol 2. Scripps Institution of Oceanography. The University of California. La Jolla. California. p 195. 